\title{
及2-adrenergic receptor signaling promotes neuroblastoma cell proliferation by activating autophagy
}

\author{
JING DENG $^{1 *}$, PING JIANG ${ }^{1 *}$, TIANYOU YANG ${ }^{2 *}$, MAO HUANG $^{1}$, JINYE XIE $^{1}$, CHUANGHUA LUO $^{1}$, \\ WEIWEI QI ${ }^{1}$, TI ZHOU ${ }^{1}$, ZHONGHAN YANG ${ }^{1}$, YAN ZOU ${ }^{2}$, GUOQUAN GAO $^{1-3}$ and XIA YANG ${ }^{1,2,4}$
}

\begin{abstract}
${ }^{1}$ Department of Biochemistry, Zhongshan School of Medicine, Sun Yat-Sen University; ${ }^{2}$ Program of Molecular Medicine, Department of Internal Medicine, Affiliated Guangzhou Women and Children's Medical Center, Zhongshan School of Medicine, Sun Yat-Sen University; ${ }^{3}$ Guangdong Province Key Laboratory of Brain Function and Disease, Zhongshan School of Medicine, Sun Yat-Sen University; ${ }^{4}$ Guangdong Engineering and Technology Research Center for Gene Manipulation and Biomacromolecular Products, Sun Yat-Sen University, Guangzhou, Guangdong 510080, P.R. China
\end{abstract}

Received February 23, 2019; Accepted June 26, 2019

DOI: $10.3892 / o r .2019 .7266$

\begin{abstract}
Accumulating evidence suggests the pivotal role of the sympathetic nervous system in the initiation and aggressive progression of tumors, whereas the role of $\beta$-adrenergic receptor ( $\beta$-AR) signaling in neuroblastoma (NB) and the underlying regulatory mechanisms have not yet been well elucidated. In the present study, it was demonstrated that the expression of both $\beta 1-\mathrm{AR}$ and $\beta 2-\mathrm{AR}$ was significantly increased in clinical samples of NB compared with those of ganglioneuroma (GN) and ganglioneuroblastoma (GNB), and that $\beta 2$-AR is the key $\beta$-adrenergic receptor responsible for NB cell growth. Further investigation showed that the expression levels of the autophagy markers LC3-II, beclin-1 and unc-51-like autophagy kinase 1 (ULK1) were also elevated in $\mathrm{NB}$, compared to the cases of GN and GNB. Moreover, $\beta 2-\mathrm{AR}$ expression was found to be positively associated with autophagy markers in the clinical NB specimens. Cellular functional assays demonstrated that $\beta 2$-AR activation promoted NB cell growth and activated the autophagy pathway. Pharmacological inhibition of autophagy with 3-methyladenine abolished $\beta 2$-AR-induced NB cell growth. Mechanistically, $\beta 2$-AR signaling triggers autophagy through CREB-mediated ULK1 upregulation. In conclusion, the present study uncovered a novel regulatory mechanism of $\beta 2$-AR-activated autophagy in NB cell growth and provides a novel potential therapeutic
\end{abstract}

Correspondence to: Professor Xia Yang or Professor Guoquan Gao, Department of Biochemistry, Zhongshan School of Medicine, Sun Yat-sen University, 74 Zhongshan 2nd Road, Guangzhou, Guangdong 510080, P.R. China

E-mail: yangxia@mail.sysu.edu.cn

E-mail: gaogq@mail.sysu.edu.cn

*Contributed equally

Key words: neuroblastoma, $\beta$-adrenergic receptor, autophagy, proliferation, CREB approach for treating NB by targeting autophagy and the $\beta 2-A R$ pathway.

\section{Introduction}

Neuroblastoma (NB) is the most common extracranial solid tumor in children; it is derived from the primary neural crest. NB accounts for 6-10\% of all cancers diagnosed in children, and causes $9-15 \%$ of all cancer-related deaths in childhood (1-4). The biological behavior of NB is dramatically heterogeneous in clinical settings, spanning from spontaneous regression of low-risk NB to aggressive progression to high-risk clinical stage $(5,6)$. There are various biological prognostic markers that are used to predict poor outcomes following the diagnosis of NB, including the amplification of the proto-oncogene N-MYC, dysregulation of anaplastic lymphoma kinase (ALK) and genetic aberrations. The amplification of N-MYC usually predicts an unfavorable prognosis in patients with NB (7-12). Although intensive therapies have been utilized to treat this malignancy, the recurrence and metastatic rates of high-risk NB are still extremely high and are responsible for $50 \%$ of the mortality of NB patients (2). Given the poor prognosis of high-risk NB, there is an urgent need to further investigate the mechanisms underlying the initiation and aggressive progression of NB, hoping to identify more effective therapeutic targets.

$\beta$-adrenergic receptor ( $\beta$-AR) signaling plays an important role in the regulation of physiological and pathological processes $(13,14)$. For instance, it is significantly involved in the modulation of the cardiovascular system, lipid metabolism and immune homeostasis (15-18). $\beta$-AR signaling is activated by the binding of $\beta$-AR with catecholamine hormones including adrenaline and norepinephrine, and catecholamine hormones are usually secreted under stressful conditions (19). Recent studies have revealed that $\beta$-AR signaling is also involved in tumorigenesis and metastasis (20-23). For example, it has been documented that the activation of $\beta$-AR signaling can promote hepatocellular carcinoma cell growth in vitro and in vivo (24). Either the use of $\beta$-AR antagonists or the genetic deletion of $\beta 2-$ and $\beta 3-A R$ in stromal cells has been shown to suppress the 
early metastasis of prostate cancer (25). $\beta$-AR blockers have been used for treating hypertension for decades, and they have exhibited a notable antitumor efficacy in clinical trials $(26,27)$. However, the role of the $\beta$-AR pathway in the tumorigenesis and progression of $\mathrm{NB}$, which is a type of neural system tumor, is not clear, and the underlying regulatory mechanisms have not been well studied. Thus, it is necessary to investigate the role of $\beta$-AR signaling in NB and the novel mechanisms underlying the $\beta$-AR-mediated regulation of NB.

Autophagy is an evolutionarily conserved catabolic process by which cells capture, deliver, degrade and recycle damaged protein aggregates and organelles to sustain metabolic homeostasis; it helps the cells survive stressful conditions such as nutrient deprivation (28-30). There are three main types of autophagy: Macro-autophagy, micro-autophagy, and chaperone-mediated autophagy (31). Hereafter, the term 'autophagy' refers to macro-autophagy. A normal, basal level of autophagy is important for the timely clearance of unfavorable cellular components to prevent the buildup of toxic materials $(32,33)$, while the deregulation of autophagy is closely associated with multiple diseases including cancer, inflammation, and neurodegenerative diseases $(34,35)$. The role of autophagy in tumors is really complex and context-dependent. Autophagy can promote or suppress tumorigenesis and the aggressive progression of tumors based on the tumor microenvironment. For instance, the ablation of $\mathrm{Atg}^{7^{+/}}$tumor cells in a $\mathrm{KRAS}^{\mathrm{G} 12 \mathrm{D}}$ mutation-driven lung cancer mouse model has been shown to be accompanied by the accumulation of defective mitochondria and cell growth arrest, resulting in the inhibition of tumorigenesis (36). On the other hand, autophagy defects can lead to genomic instability, activation of DNA damage response, and oxidative stress, which can contribute to tumorigenesis and tumor progression (37). In NB, it has been reported that the targeted inhibition of the autophagy-related protein unc-51-like autophagy kinase 1 (ULK1) can promote NB cell apoptosis and suppress NB cell growth (38). It is known that autophagy is usually activated upon starvation; however, whether autophagy can be stimulated under stressful conditions in NB has not yet been reported. Thus, in the present study, we aimed to investigate the novel underlying regulatory mechanisms of autophagy in NB.

Importantly, we used clinical tumor samples and cellular assays to ascertain the role of $\beta$-AR signaling and autophagy in $\mathrm{NB}$, hoping to uncover a novel regulatory mechanism involving the $\beta$-AR pathway and autophagy, and provide potential therapeutic targets for treating NB.

\section{Materials and methods}

Reagents and antibodies. Isoprenaline (ISO, I5627), formoterol (product no. F9552), ICI118,551 (product no. I127), atenolol (product no. A7655) and 3-methyladenine (3-MA, product no. M9281) were procured from Sigma-Aldrich/Merck. SBI-0206965 was procured from Selleck Chemicals. Antibodies for $\beta 1$-AR (product no. ab3442), $\beta 2-A R$ (product no. ab182136), N-MYC (product no. ab24193), and Beclin-1 (product no. ab109631 for IHC assay) were obtained from Abcam. Antibodies for LC3B (product no. 3868), beclin-1 (product no. 3495), CREB (product no. 48H2),
p-CREB (product no. 87G3), p-ULK1 (product no. 5869S) and ULK1 (product no. 8054T) were obtained from Cell Signaling Technology. LC3-II (cat. no. A11923) for IHC staining was purchased from Abclonal. ULK1 for the IHC assay was obtained from Zen BioScience.

Clinical samples and immunohistochemistry (IHC) assay. The clinical samples of ganglioneuroma (GN), ganglioneuroblastoma (GNB, nodular and intermixed), and NB were obtained from the Guangzhou Women and Children's Medical Center (26, 34 and 71 samples, respectively). The date range of sample collection was from January 2003 to September 2015. These samples were used for constructing tissue microarrays (TMAs) by the Shanghai Outdo Biotech Company. The clinical information of these samples is documented in Table I. For the IHC staining of the TMAs, the clinical tumor samples were fixed and then embedded in paraffin. The tissue slides were treated with endogenous peroxidase blocking solution and normal goat serum to block nonspecific background interactions. Then, the tissues were incubated with anti- $\beta 1-A R$ (dilution 1:200), - $\beta 2$-AR (dilution 1:200), -ULK1 (dilution 1:200), -beclin-1 (dilution 1:200) and -LC3-II (dilution 1:200) antibodies at $4^{\circ} \mathrm{C}$ overnight. After incubation with the primary antibodies, the slides were incubated with horseradish peroxidase-labeled anti-rabbit or mouse secondary antibodies for $30 \mathrm{~min}$ at room temperature; they were then stained with the chromogenic substrate diaminobenzidine (DAB; Dako; Agilent Technologies, Inc.), and counterstained with hematoxylin. The evaluation of tissue microarray scores was carried out by two independent researchers based on the positive staining intensity and the percentage of positively stained cells. The IHC results were scored as 0 (negative), 1-2 (weakly positive), 3-4 (moderately positive), 5-6 (strongly positive), and high expression of tumor cells were defined as scores $>3$.

This study was approved by the Human Ethics Committee of the Affiliated Guangzhou Women and Children's Medical Center, Zhongshan School of Medicine. All patients gave informed consent before participation in the present study.

Cell culture. NB cells including SK-N-AS, SK-N-SH, SHEP, SK-N-BE2, SK-N-BE2c and Kelly was used as cell models. Among these cell lines SK-N-AS, SK-N-SH and SHEP were N-MYC non-amplified cells, while SK-N-BE2, SK-N-BE2c and Kelly were N-MYC amplified cells. These cell lines were a kind gift from Professor Li Bo, Sun Yat-Sen Medical School. These cells were cultured in high-glucose Dulbecco's modified Eagle's medium (DMEM; Corning, Inc.) supplemented with $10 \%$ heat-inactivated fetal bovine serum (FBS; Gibco; Thermo Fisher Scientific, Inc.) at $37^{\circ} \mathrm{C}$ and $5 \% \mathrm{CO}_{2}$ conditions in a humidified incubator.

CCK-8 assay. For the CCK-8 assay, SK-N-BE2 and Kelly cells were seeded into 96 -well plates at densities of $3 \times 10^{3}$ and $5 \times 10^{3}$ cells per well, respectively. These cells were treated with selective and non-selective $\beta$-AR agonists and antagonists including isoprenaline, ICI118,551 and atenolol for the indicated time periods. Then, the absorbance of the samples was detected at $450 \mathrm{~nm}$ according to the manufacturer's instructions. 
Table I. Clinical information of the GN, GNB and NB samples.

\begin{tabular}{|c|c|c|c|c|c|}
\hline Tumor & Age & Sex & N-MYC status & INSS & Total no. \\
\hline NB & $\begin{array}{l}<18 \text { months }(43) \\
>18 \text { months }(28)\end{array}$ & $\begin{array}{l}\text { Male (43) } \\
\text { Female (28) }\end{array}$ & $\begin{array}{l}\text { Amplified (8) } \\
\text { Non-amplified (37) }\end{array}$ & $\begin{array}{l}\text { I (29) } \\
\text { II (15) } \\
\text { III (10) } \\
\text { IV (13) }\end{array}$ & 71 \\
\hline GNB & $\begin{array}{l}<18 \text { months }(5) \\
>18 \text { months }(29)\end{array}$ & $\begin{array}{l}\text { Male (16) } \\
\text { Female (18) }\end{array}$ & $\begin{array}{l}\text { Amplified (2) } \\
\text { Non-amplified (17) }\end{array}$ & $\begin{array}{l}\text { I (11) } \\
\text { II (9) } \\
\text { III (4) } \\
\text { IV (7) }\end{array}$ & 34 \\
\hline GN & $\begin{array}{l}<18 \text { months }- \\
>18 \text { months }(26)\end{array}$ & $\begin{array}{l}\text { Male (10) } \\
\text { Female (16) }\end{array}$ & $\begin{array}{l}\text { Amplified - } \\
\text { Non-amplified (3) }\end{array}$ & $\begin{array}{l}\text { I (16) } \\
\text { II (5) } \\
\text { III - } \\
\text { IV - }\end{array}$ & 26 \\
\hline
\end{tabular}

NB, neuroblastoma; GNB, ganglioneuroblastoma; GN, ganglioneuroma; INSS, International Neuroblastoma Staging System.

Western blot assay. Proteins from NB cells were harvested using lysis buffer (glycerol, $0.5 \mathrm{M}$ Tris-HCl, 10\% SDS, $\mathrm{ddH}_{2} \mathrm{O}$ ), and the protein concentrations were detected using the BCA kit. Then, the protein samples were treated with 10X loading buffer $(0.2 \%$ bromophenol blue, $\beta$-mercaptoethanol) and $30 \mu \mathrm{g}$ protein was separated on 10 and $15 \%$ SDS-PAGE gels; the resulting protein bands were transferred onto PVDF membranes. The membranes were blocked with 5\% skimmed milk for $1 \mathrm{~h}$ at room temperature. Then, they were incubated with the indicated antibodies anti- $\beta 1-A R$ (dilution 1:1,000), - $\beta 2-A R$ (dilution 1:1,000), -ULK1 (dilution 1:1,000), -p-ULK1 (dilution 1:1,000), CREB (dilution 1:1,000), p-CREB (dilution 1:1,000), -LC3-II (dilution 1:1,000), N-MYC (dilution $1: 1,000$ ) and $\beta$-actin (dilution 1:6,000) at $4^{\circ} \mathrm{C}$ overnight with shaking, followed by incubation with horseradish peroxidase (HRP)-labeled secondary antibodies (dilution 1:3,000) for $2 \mathrm{~h}$ at room temperature. The enhanced chemiluminescent (ECL) kit (P90720; Millipore) was used to visualize the western blot results, and ImageJ (x64; National Institutes of Health, Bethesda, MD, USA) software was applied to quantify the densitometry.

EdU assay and autophagic flux detection. For EdU staining, a total number of $2 \times 10^{5}$ SK-N-BE2 and Kelly cells were mounted onto coverslips in 6-well plates. After being cultured for $24 \mathrm{~h}$, the cells were treated with the indicated reagents for another $24 \mathrm{~h}$. Then, they were incubated with EdU reagents (Nanjing KeyGen Biotech Co., Ltd.) for $2 \mathrm{~h}$, followed by subsequent staining according to the manufacturer's instructions. The images were captured using a fluorescence microscope at a magnification of x100 (Olympus BX63; Olympus Corp., Tokyo, Japan). A recombinant adenovirus expression vector containing tandem RFP-GFP-LC3 (Hanbio Biotechnology Co.) was used to assess the change of autophagic flux. The MOI was 100 , and the cells were incubated with the adenoviruses for $24 \mathrm{~h}$ before the subsequent treatments. The images were obtained using a confocal microscope at a magnification of x630 (LSM 780; Carl Zeiss).
Transfection with small interfering RNA (siRNA). siRNAs were used to knock down the expression of $\beta 2-\mathrm{AR}$ and $C R E B$. The siRNAs were synthesized by Guangzhou RiboBio Co., Ltd. (Guangzhou, China). For interfering with the functions of $\beta 2-A R$ and CREB, SK-N-BE2 cells were seeded into 6 -well plates at a density of $5 \times 10^{5}$ cells per well, and transfected with $100 \mathrm{nM}$ of the respective siRNAs using the transfection reagent RNAiMAX (Invitrogen; Thermo Fisher Scientific, Inc.), according to the manufacturer's instructions. After culturing the cells for $48 \mathrm{~h}$, the interference efficiency was verified by western blotting; the cells were subjected to the subsequent treatments based on the above methods. The siRNA sequences of $\beta 2-A R$ and CREB used in our experiments are as follows: $\beta 2-A R$ (CATCCTCCTAAATTGGATA) and CREB (siRNA1, CGTAGAAAGAAGAAAGAAT; siRNA2, GCCACAGATTGCCACATTA; and siRNA3, GCAATACAG CTGGCTAACA).

Statistical analysis. Student's t-test and one-way ANOVA with post hoc contrasts by a Newman-Keuls test were used to assess the differences between two or three groups by means of GraphPad Prism 5 software (GraphPad Software, Inc.). P-values $<0.05$ were considered statistically significant.

\section{Results}

Expression of $\beta 1$ - and $\beta 2-A R$ is significantly increased in $N B$. To investigate the role of $\beta$-AR in NB, we first detected the expression of $\beta$-AR in the clinical tumor samples. The expression of $\beta$-adrenergic receptors was detected in samples of three peripheral neuroblastic tumors (PNTs) including GN, GNB (nodular and intermixed) and NB. Among these subtypes, NB is the most malignant and consistently shows an unfavorable prognosis and low survival rate; the other two types of tumors consistently exhibit a good prognosis compared to NB (9). $\beta$-AR includes $\beta 1-A R, \beta 2-A R$ and $\beta 3-A R$. We mainly tested the expression of $\beta 1-A R$ and $\beta 2-A R$ in our study. IHC results using the TMA samples revealed that the levels of $\beta 1-A R$ and 
A

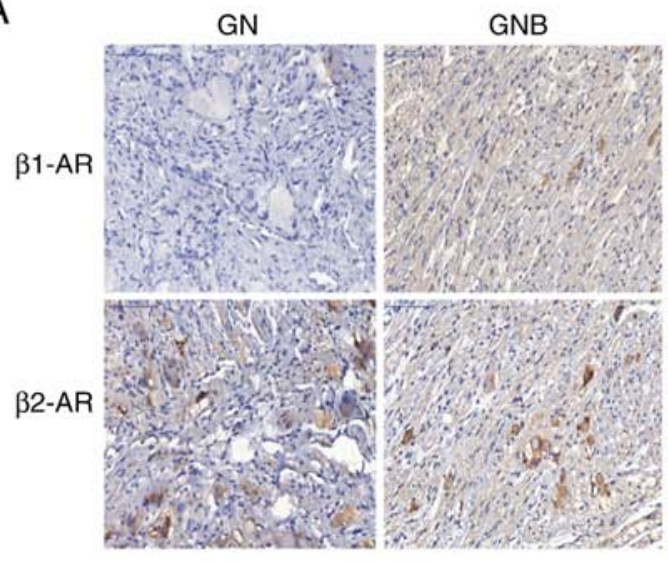

GN
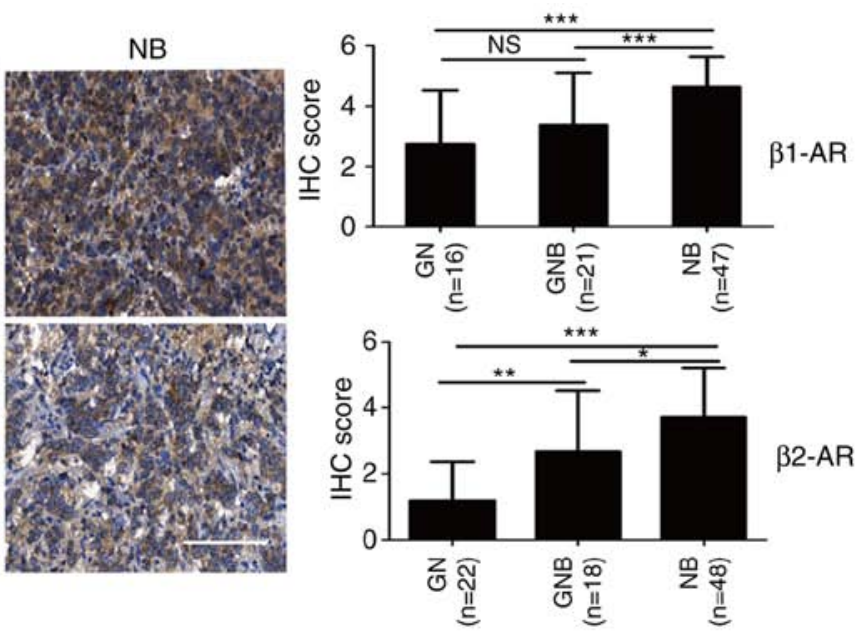

B

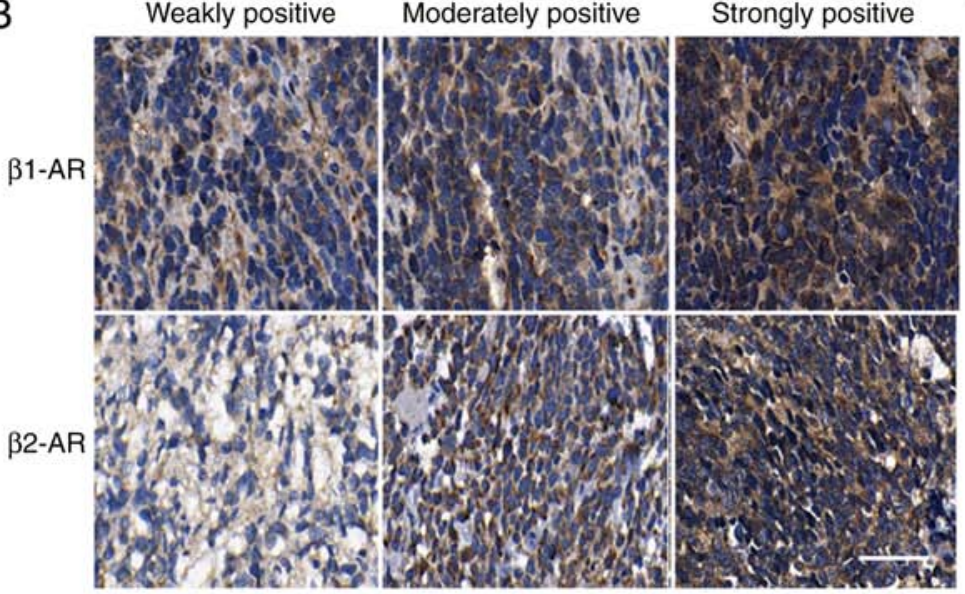

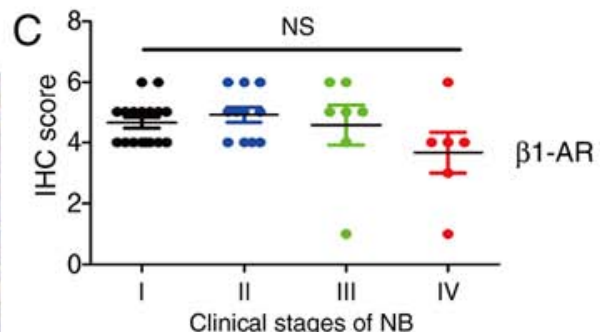

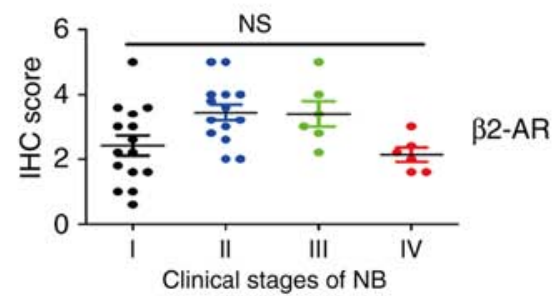

Figure 1. Expression of $\beta 2$-AR is significantly increased in the neuroblastoma tissues. (A) IHC staining was used to assess the levels of $\beta 1$-AR and $\beta 2-A R$ in tissue microarrays, and the IHC scores were calculated. Scale bar, $100 \mu \mathrm{m}$. (B) Representative images of IHC staining scores are shown. Scale bar, $50 \mu \mathrm{m}$. (C) Correlation between the $\beta 1$-AR and $\beta 2$-AR levels in NB of different clinical stages is shown. Student's unpaired t-test was used to assess the difference between two groups. All values are expressed as the mean \pm SEM. The experiment was repeated three times. ${ }^{*} \mathrm{P}<0.05,{ }^{* *} \mathrm{P}<0.01,{ }^{* * *} \mathrm{P}<0.001$. NS, not significant. IHC, immunohistochemistry; NB, neuroblastoma; GN, ganglioneuroma; GNB, ganglioneuroblastoma; $\beta$-AR, $\beta$-adrenergic receptor.

$\beta 2-A R$ were significantly upregulated in the NB samples, compared to the levels noted in the GN and GNB samples (Fig. 1A). The representative images of IHC staining scores of clinical NB samples are shown in Fig. 1B. We further evaluated the expression of $\beta 1-A R$ and $\beta 2-A R$ in different clinical stages of NB, but there was no notable correlation between the $\beta 1-A R$ and $\beta 2-A R$ expression in the different clinical stages of NB (Fig. 1C). This result suggests that the $\beta$-AR pathway may play a crucial role in the tumorigenesis of NB.

Activation of $\beta 2-A R$ signaling promotes NB cell proliferation. To further investigate the role of $\beta$-AR signaling pathway in NB cell growth, the expression of $\beta 1-A R, \beta 2-A R$ and N-MYC was detected in six different NB cell lines. The amplification status of N-MYC is an important prognostic marker for NB. The expression levels of $\beta 1-\mathrm{AR}$ and $\beta 2-\mathrm{AR}$ in six NB cell lines are shown in Fig. 2A. We chose two cell lines SK-N-BE2 and Kelly which express high level of $\beta 2-A R$ as cell models. Treatment with the non-selective $\beta$-AR agonist isoprenaline (ISO) increased the viability of the NB SK-N-BE2 and Kelly cell lines (Fig. 2B and C). In order to demonstrate which $\beta$-AR is responsible for the promotive effect of $\beta$-AR activation on cell survival, we utilized specific antagonists of $\beta 1$-AR (atenolol) and $\beta 2-A R(I C I 118,551)$ to ascertain the role of the $\beta$-AR pathway in NB cell growth. The results showed that treatment with the $\beta 1-A R$ antagonist atenolol did not affect NB cell survival, while treatment with the $\beta 2-\mathrm{AR}$ antagonist ICI118,551 suppressed the cell viability in a concentration-dependent manner (Fig. 2D). These findings demonstrate that the increased proliferation of NB cells induced by $\beta$-AR activation occurs through $\beta 2$-AR signaling. However, the mechanisms underlying the promotive role of the $\beta 2$-AR pathway on NB cell proliferation have not yet been clarified.

Expression of autophagy markers is significantly increased in NB. Considerable research has demonstrated the critical role of the autophagy pathway in the initiation and progression of tumors, and autophagy plays a dual role in tumorigenesis and metastasis. To study the role of autophagy in NB, we assessed the expression of the important autophagy markers ULK1, beclin-1 and microtubule-associated protein 1 light chain 3-II (LC3-II) in the clinical tumor samples. ULK1 is a serine/threonine-protein kinase, and the activation of ULK1 can initiate autophagy via the phosphorylation of beclin-1 and 

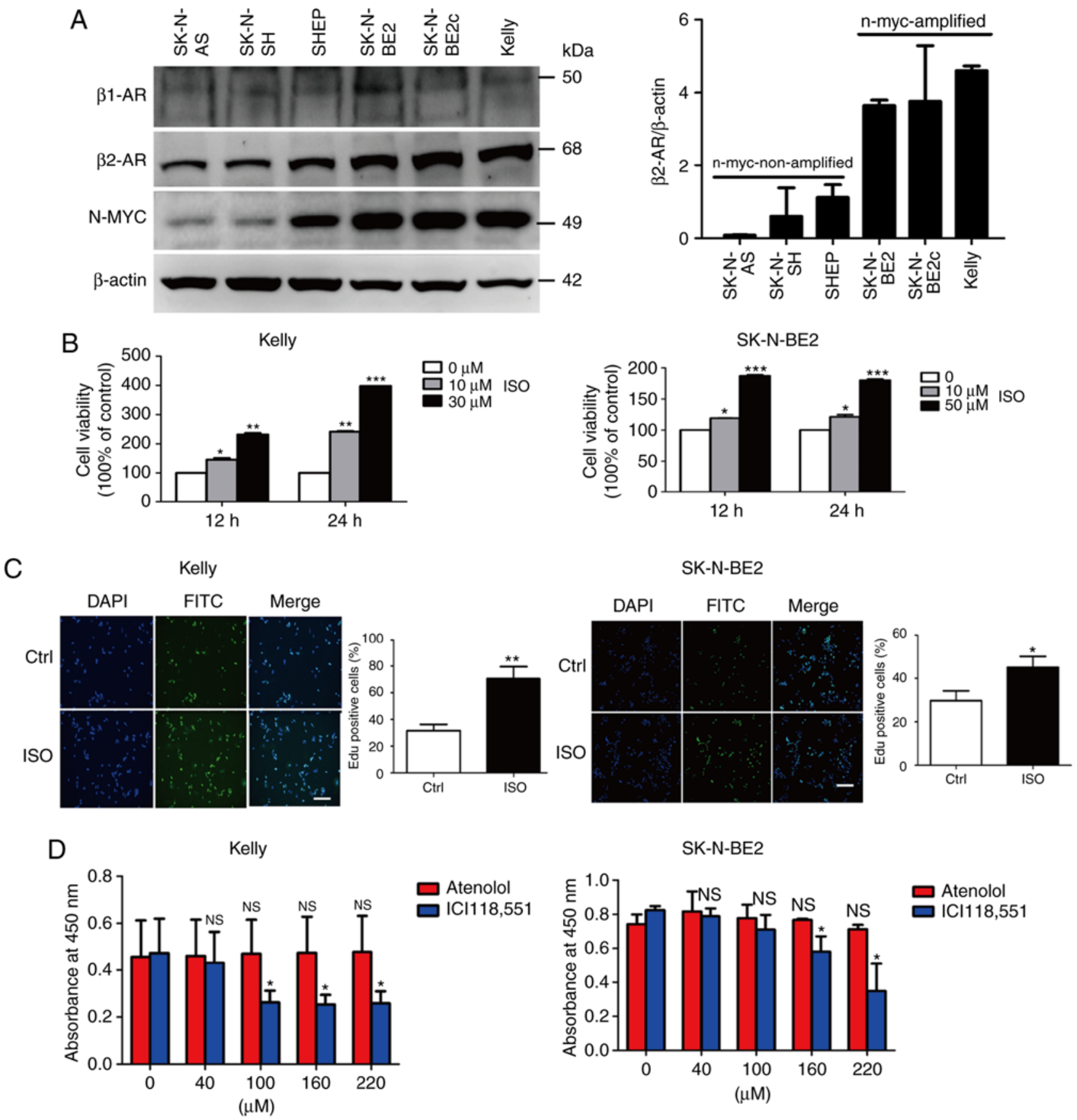

Figure 2. Stimulation of NB cell lines with ISO promotes their proliferation. (A) The protein expression of $\beta 1-\mathrm{AR}, \beta 2-\mathrm{AR}$ and N-MYC was evaluated in six types of NB cells using western blot assay. (B) SK-N-BE2 cells were treated with 10 and $50 \mu \mathrm{M}$ ISO, and Kelly cells were treated with 10 and $30 \mu \mathrm{M}$ ISO for 12 and $24 \mathrm{~h}$; CCK-8 assay was used to analyze the cell viability. (C) SK-N-BE2 and Kelly cells were treated with $10 \mu$ M ISO, and EdU assay was performed to test the proliferation of the ISO-treated cells. (D) NB cells were treated with different concentrations of atenolol or ICI118,551 for $24 \mathrm{~h}$, and then cell viability was detected via the CCK-8 assay. Scale bar, $100 \mu \mathrm{m}$. Data are expressed as the mean \pm SEM of three experiments. Student's unpaired t-test was used to assess the difference between two groups. Multigroup comparisons of the means were carried out by one-way analysis of variance (ANOVA) test with post hoc contrasts by a Newman-Keuls test. ${ }^{*} \mathrm{P}<0.05,{ }^{* *} \mathrm{P}<0.01,{ }^{* * * *} \mathrm{P}<0.001$. $\beta$-AR, $\beta$-adrenergic receptor; ISO, agonist isoprenaline; MYCN, MYCN proto-oncogene, BHLH transcription factor; NB, neuroblastoma.

the subsequent enhancement of the formation and activity of the autophagic complex Atg14/beclin-1/VPS34 (39). LC3-II is located in the autophagosome and promotes the fusion of autophagosomes with lysosomes, leading to the formation of autolysosomes. The IHC results showed that the levels of ULK1, beclin-1 and LC3-II were significantly increased in the clinical samples of $\mathrm{NB}$, compared to these levels in the GN and GNB samples (Fig. 3). Clinical correlation analysis revealed that the expression of ULK1, beclin-1 and LC3-II correlated positively with that of $\beta 2-\mathrm{AR}$, but not $\beta 1$-AR (Tables II and III), implying that there is a crosstalk between the $\beta 2$-AR pathway and autophagy in NB. Thus, we further investigated the role of $\beta 2$-AR signaling in regulating autophagy in NB cells.

$\beta 2-A R$ signaling activates the autophagy pathway in $N B$ cells. To explore the role of $\beta$-AR in autophagy, NB cells were 

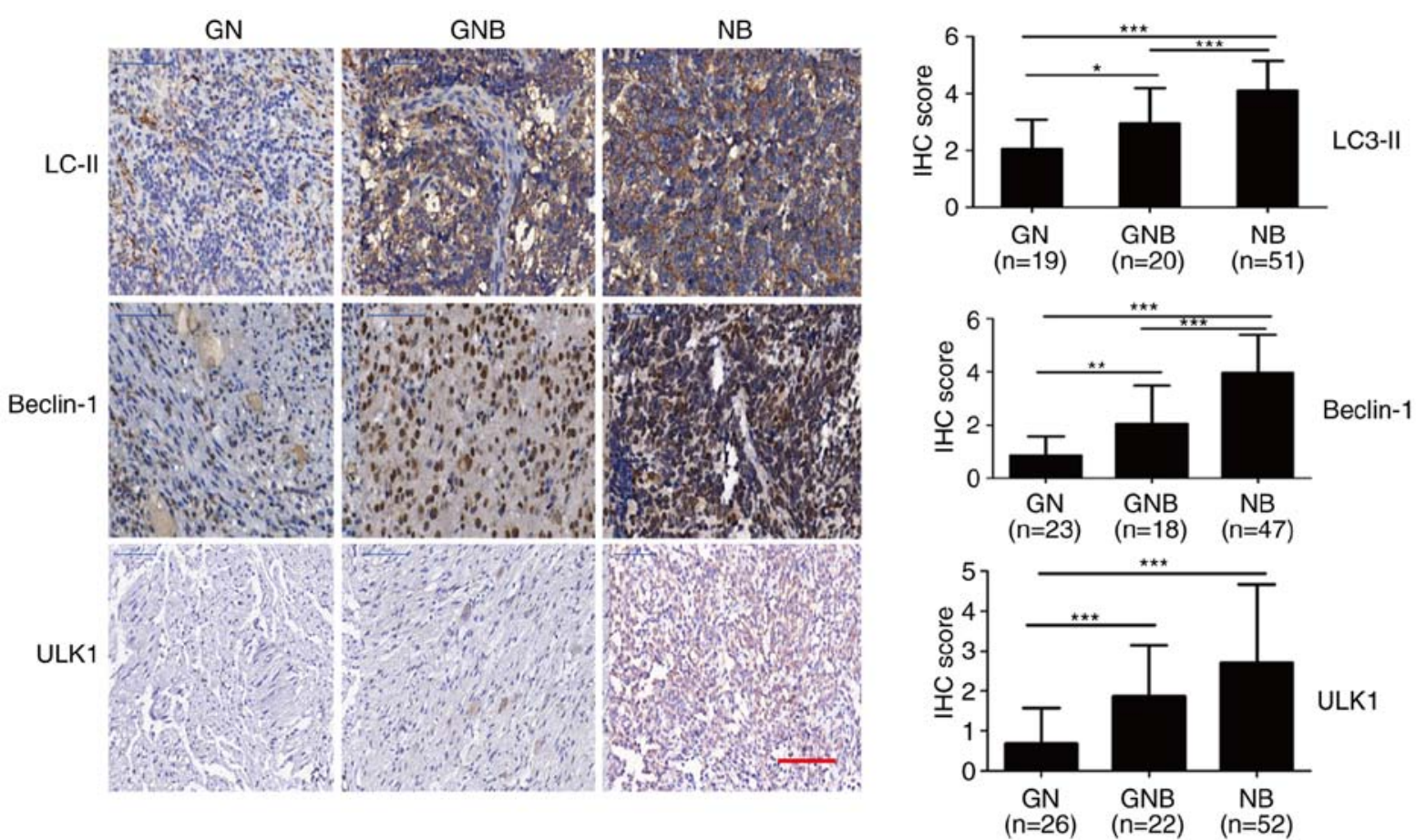

Figure 3. $\beta 2$-AR expression is positively correlated with autophagy markers in NB. The expression levels of the autophagy markers ULK1, beclin-1 and LC3-II were markedly elevated in the NB samples, compared to the levels noted in the GN and GNB samples. Scale bar, $100 \mu \mathrm{m}$. Student's unpaired t-test was used to assess the difference between two groups. All values are expressed as the mean \pm SEM. The experiment was repeated three times. ${ }^{*} \mathrm{P}<0.05,{ }^{* *} \mathrm{P}<0.01$, ${ }^{* * * *} \mathrm{P}<0.001$. IHC, immunohistochemistry; NB, neuroblastoma; GN, ganglioneuroma; GNB, ganglioneuroblastoma; $\beta$-AR, $\beta$-adrenergic receptor; ULK1, unc-51-like autophagy kinase 1; LC3-II, microtubule-associated protein 1 light chain 3-II.
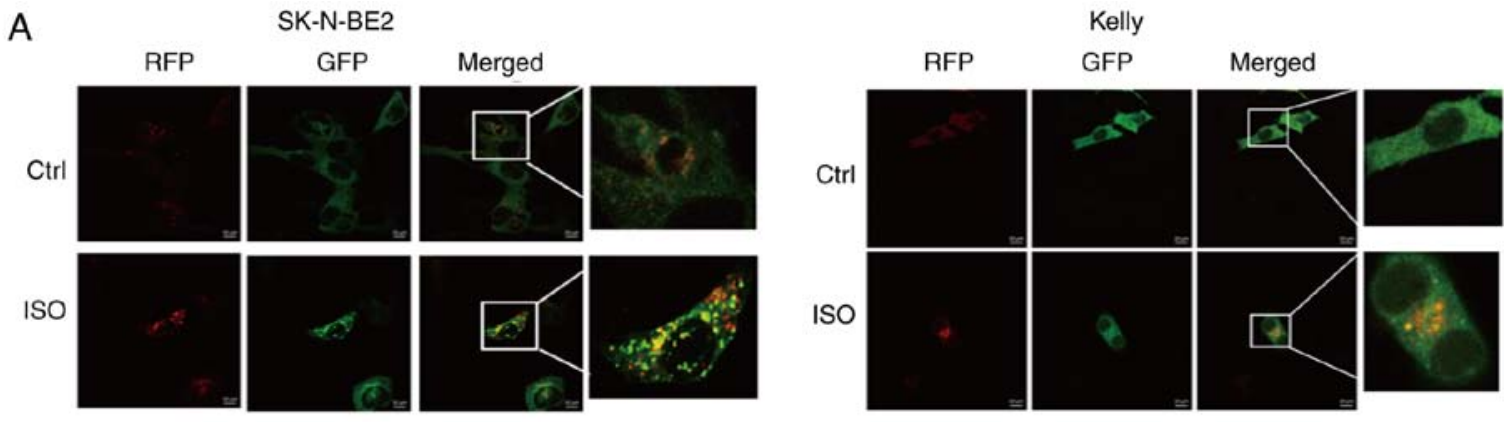

B

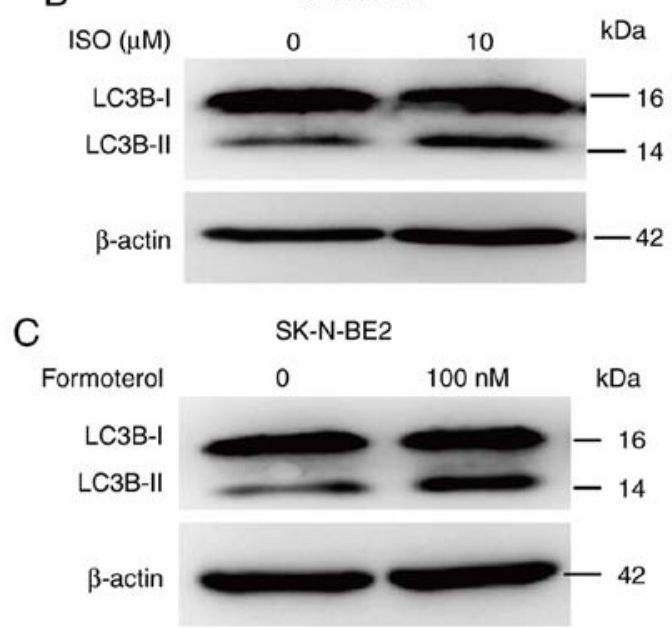

Kelly

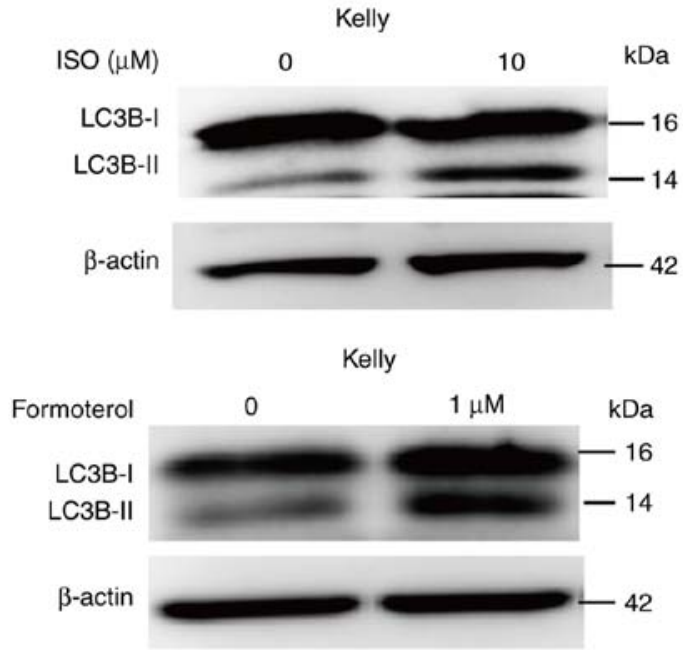

Figure 4. 32 -AR activation induces autophagy in NB cells. (A) NB cells were infected with GFP-RFP-LC3-labeled adenoviruses, and the formation of yellow (autophagosomes) and red (autolysosomes) vacuoles was observed by confocal microscopy; scale bar, $10 \mu \mathrm{m}$. (B) Neuroblastoma cells were treated with ISO for $24 \mathrm{~h}$, and western blot analysis was performed to detect the expression of LC3B-I and LC3B-II. (C) Cells were stimulated with the specific $\beta 2-\mathrm{AR}$ agonist formoterol and the levels of LC3B-I and LC3B-II were assessed by western blot analysis. Experiments were performed three times and representative images are shown. NB, neuroblastoma; $\beta$-AR, $\beta$-adrenergic receptor; LC3-II, microtubule-associated protein 1 light chain 3-II; ISO, isoprenaline. 
Table II. Correlation of $\beta 1$-AR with autophagic markers.

\begin{tabular}{lccc}
\hline & \multicolumn{3}{c}{$\beta 1$-AR } \\
\cline { 2 - 4 } & Mean $\pm \mathrm{SD}$ & $\mathrm{r}$ & P-value \\
\hline LC3-II & $0.88 \pm 4.15$ & 0.31 & 0.05 \\
Beclin-1 & $4.07 \pm 0.34$ & 0.24 & 0.14 \\
ULK1 & $3.28 \pm 1.77$ & 0.24 & 0.14
\end{tabular}

$\beta 1$-AR, $\beta 1$-adrenergic receptor; ULK1, unc-51-like autophagy kinase 1; LC3-II, microtubule-associated protein 1 light chain 3-II.

Table III. Correlation of $\beta 2$-AR with autophagic markers.

\begin{tabular}{lccc}
\hline & \multicolumn{3}{c}{$\beta 1-\mathrm{AR}$} \\
\cline { 2 - 4 } & Mean $\pm \mathrm{SD}$ & $\mathrm{r}$ & P-value \\
\hline LC3-II & $4.19 \pm 0.86$ & 0.47 & 0.001 \\
Beclin-1 & $4.21 \pm 1.23$ & 0.40 & 0.01 \\
ULK1 & $3.27 \pm 1.70$ & 0.36 & 0.03 \\
\hline
\end{tabular}

$\beta 2$-AR, $\beta 2$-adrenergic receptor; ULK1, unc-51-like autophagy kinase 1; LC3-II, microtubule-associated protein 1 light chain 3-II.

stimulated with the $\beta$-AR agonist ISO, and then expression of the autophagy marker LC3 was detected. Upon its synthesis, LC3 is immediately cleaved by Atg4 and is converted to its cytoplasmic form LC3-I. During autophagy activation, cytoplasmic LC3-I is conjugated with phosphatidylethanolamine (PE) by the action of Atg3 and Atg7, and is then translocated into the membranes of autophagosomes, turning into autophagic LC3-II; thus, it promotes the elongation and maturation of autophagosomes. Then, mature autophagosomes fuse with lysosomes to form autolysosomes, degrading the components within themselves. LC3-II has always been used as a molecular marker for the activation of autophagy. Firstly, we used GFP-RFP-labeled adenovirus expressing LC 3 to evaluate the change of autophagic flux. During the late stage of the autophagy process, the formation of autolysosomes causes a decrease in $\mathrm{pH}$, which results in the quenching of GFP, as GFP is sensitive to acidic conditions. The results showed that ISO treatment improved the accumulation of yellow (autophagosomes) and red (autolysosomes) vacuoles (Fig. 4A). The western blotting results suggested that the treatment of NB cells with ISO promoted the expression of LC3B-II in the SK-N-BE2 and Kelly cell lines (Fig. 4B), revealing that the activation of $\beta$-AR signaling promotes the initiation of autophagy. Treating NB cells with the specific $\beta 2$-AR agonist formoterol also promoted the expression of LC3B-II (Fig. 4C). These results suggest that the $\beta 2$-AR pathway promotes the activation of autophagy in NB cells.

Knockdown of $\beta 2-A R$ expression inhibits autophagy activation. To further investigate the role of $\beta 2$-AR on the autophagy of NB cells, we performed a genetic loss-of-function assay to determine the ISO-induced effects of $\beta 2$-AR on NB cell autophagy. We transfected NB cells with $\beta 2$-AR-specific siRNA to inhibit the expression of $\beta 2$-AR and non-specific scrambled siRNA as a control. The western blot analysis showed that the knockdown of $\beta 2$-AR suppressed the ISO-induced expression of LC3B-II (Fig. 5A). The results of the GFP-RFP-LC3-labeled adenovirus assay showed that inhibition of $\beta 2$-AR expression decreased the ISO-induced formation of yellow (autophagosomes) and red (autolysosomes) vacuoles (Fig. 5B), suggesting that $\beta$-AR signaling activates autophagy via the $\beta 2$-AR pathway.

Inhibition of autophagy suppresses NB cell growth. Our cellular functional assays demonstrated that stimulation of NB cells with ISO promoted cell growth and activated autophagy. Further clinical analysis revealed that there was a positive correlation between $\beta 2$-AR and the autophagy markers ULK1, beclin-1, and LC3-II in the clinical samples of NB. Thus, we proposed that the promotive effect of $\beta 2$-AR on NB cell proliferation may depend on autophagy. To verify this hypothesis, we inhibited autophagy using 3-MA, which is a pharmacological reagent commonly used to block the formation of the beclin-1/Atg14/VPS34 complex, leading to the prevention of autophagy activation. Our results of the CCK- 8 and EdU assays showed that treatment with 3-MA abolished the ISO-induced enhancement of NB proliferation in the Kelly and SK-N-BE2 cell lines (Fig. 6A and B). These results suggest that the $\beta 2$-AR signaling pathway promotes NB cell growth by activating the autophagy pathway.

$\beta 2-A R$ activates autophagy via CREB-regulated ULK1 expression. In order to further investigate the molecular mechanism of $\beta$-AR signaling-stimulated autophagy, we investigated the role of transcriptional factor cAMP-response element binding protein (CREB) in regulating autophagy. CREB is a downstream regulator of $\beta$-AR signaling. It has been reported that the activation of CREB under starvation conditions could directly target autophagy-related gene ulkI to induce autophagy in hepatic cells (40). As CREB is a downstream factor of $\beta$-AR signaling, thus, we hypothesized that CREB may also regulate ISO-activated autophagy in neuroblastoma. Above all, we aimed to investigate the regulatory role of CREB in ULK1 expression, which is important to clarify the regulatory mechanism of CREB in autophagy of NB cells. To verify this hypothesis, first of all, we detected the level of p-CREB in clinical samples of GN, GNB and $\mathrm{NB}$; the phosphorylation of CREB was notably upregulated in the NB samples, compared to that noted in the GN and GNB samples (Fig. 7A). Treatment of NB cells with $\beta$-AR agonist ISO promoted the phosphorylation of CREB and the autophagy-related protein ULK1 in NB SK-N-BE2 cells (Fig. 7B). Then, we used siRNA to inhibit the expression of CREB; the results of the CREB knockdown assay revealed that CREB knockdown abolished the ISO-induced enhancement of ULK1 and LC3B-II expression (Fig. 7C). As ULK1 expression is downregulated after CREB knockdown, we hypothesized that CREB activates autophagy by targeting ULK1. Further study demonstrated that use of the specific ULK1 inhibitor SBI-0206965 inhibited the ISO-induced 
A

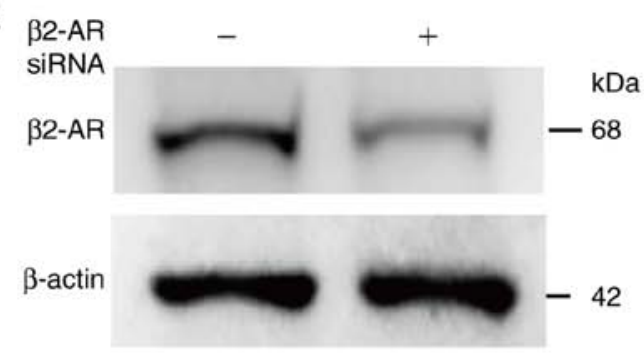

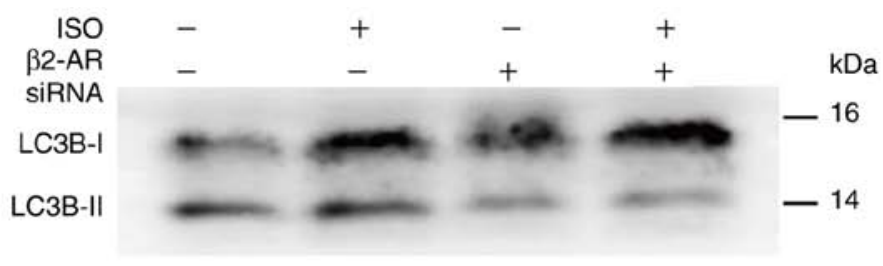

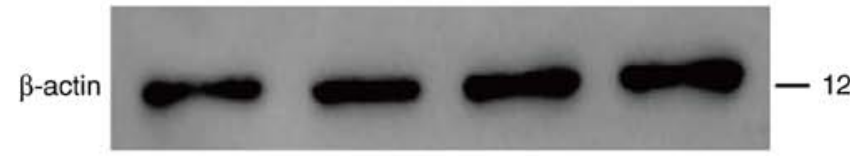

GFP
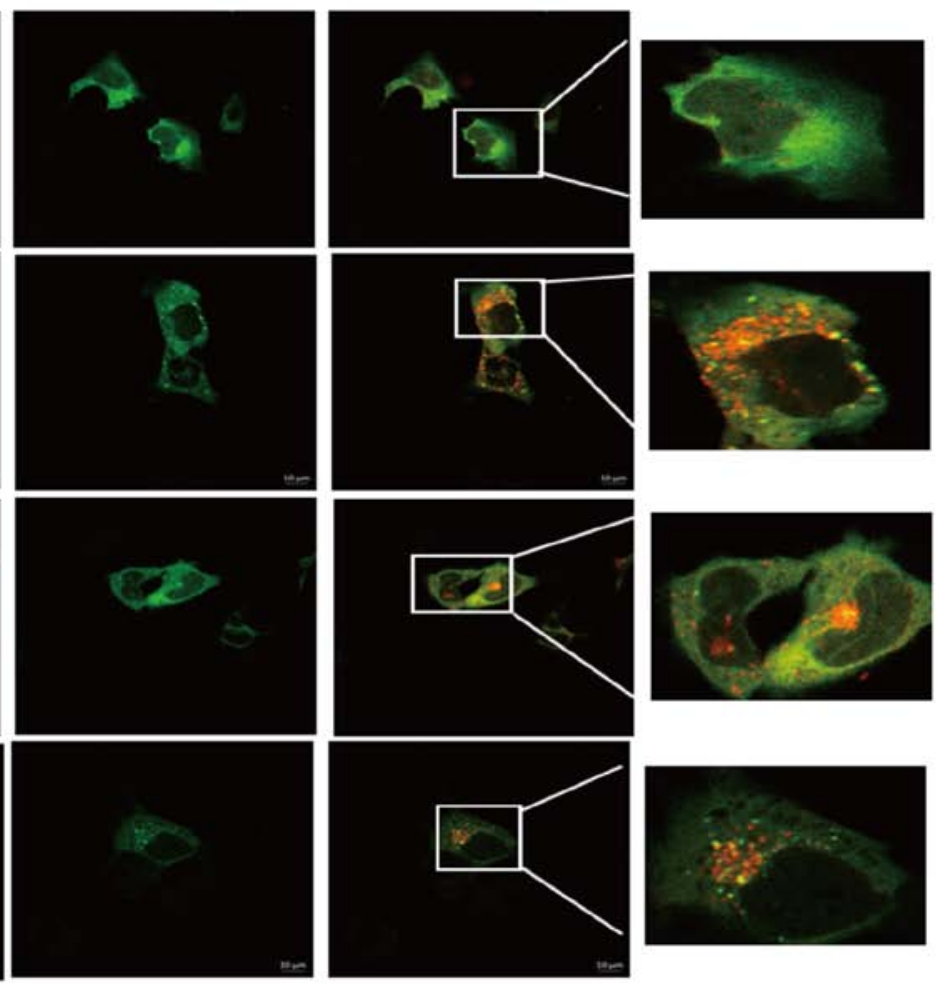

Figure 5. Knockdown of $\beta 2$-AR expression abolishes ISO-activated autophagy in NB cells. Cells were transfected with $100 \mathrm{nM} \beta 2$-AR siRNA for 24 h, and then treated with $10 \mu \mathrm{M}$ ISO for another $24 \mathrm{~h}$ and then analyzed by (A) western blot analysis and (B) confocal microscopy. Experiments were replicated thrice and representative images are shown. $\beta$-AR, $\beta$-adrenergic receptor; ISO, isoprenaline.

expression of LC3B-II (Fig. 7D), suggesting that ISO induces autophagy through CREB-mediated ULK1 expression. These results showed that $\beta$-AR activated autophagy via CREB-regulated ULK1 expression.

\section{Discussion}

Most importantly, the present study revealed that $\beta$-AR signaling is aberrantly activated in NB, and the expression of $\beta 1-A R$ and $\beta 2-A R$ is significantly enhanced in clinical samples of NB, compared to the case for those of GN and GNB. Cellular functional assays showed that $\beta 2-A R$ is the key $\beta$-adrenergic receptor responsible for NB cell growth. Clinical correlation analysis revealed that $\beta 2$-AR expression was positively associated with the autophagy markers ULK1, beclin-1 and LC3-II. Further analyses of the underlying mechanisms uncovered that activation of $\beta 2$-AR stimulated the autophagy cascade, and that the promotive effect of the $\beta 2-A R$ pathway on NB cell growth was autophagy dependent. These findings broaden our understanding of the role of autophagy and $\beta 2-\mathrm{AR}$ in NB, and clarify the involvement of a novel regulatory pathway of $\beta 2$-AR-activated autophagy in NB cell growth.

The initiation and aggressive progression of cancer are closely dependent on the tumor microenvironment, in which tumor cells can interact with other cells including myofibroblast cells, macrophages and endothelial cells, to facilitate their growth and distant dissemination (41). Many studies have reported that nerves also play an important role in modulating tumor cell survival and metastasis. For example, Magnon et al (25) found that pharmacological or surgical sympathectomy and genetic ablation of stromal cell $\beta 2-\mathrm{AR}$ and $\beta 3-A R$ prevented early-stage development of prostate cancer cells in a mouse model, suggesting that the microenvironmental nerves play a pivotal role in the initiation and distant dissemination of prostate cancer. Apart from 
A

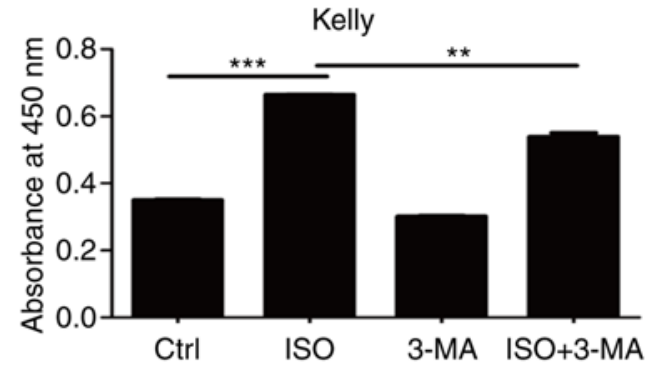

SK-N-BE2

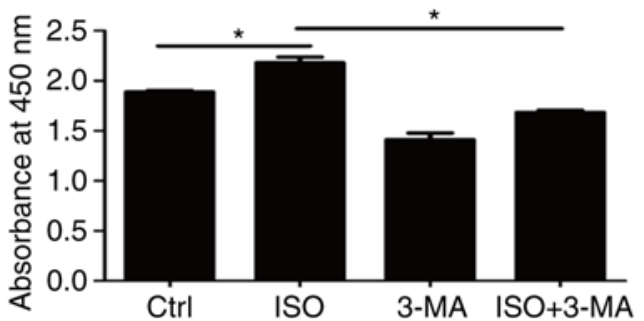

B

Kelly

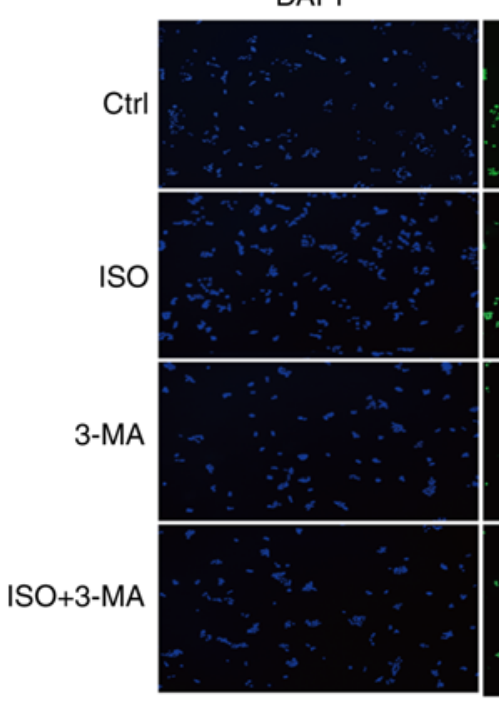

FITC
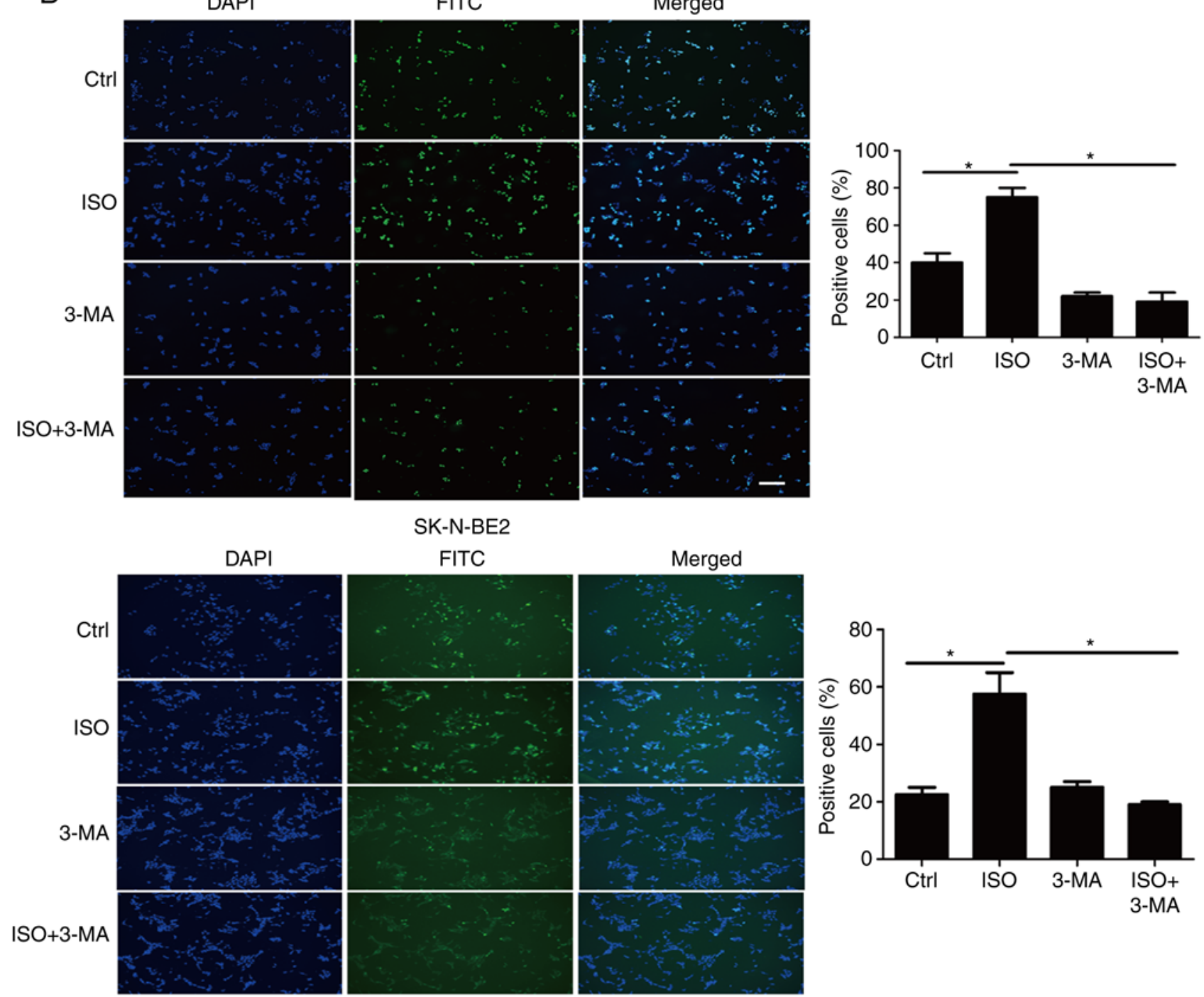

SK-N-BE2

FITC
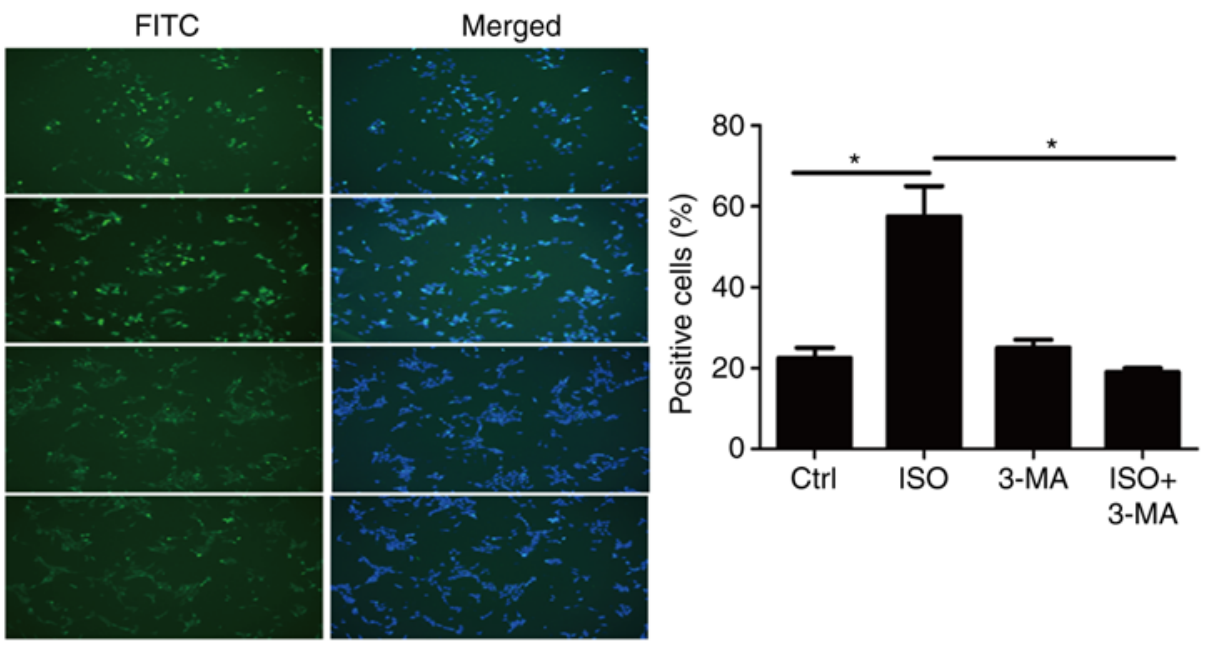

Figure 6. Inhibition of autophagy reverses the effect of ISO on cell proliferation. (A) Kelly and SK-N-BE2 cell lines were pretreated with 5 mM 3-MA for $1 \mathrm{~h}$ and then stimulated with $50 \mu \mathrm{M}$ (SK-N-BE2 cells) and $30 \mu \mathrm{M}$ ISO (Kelly cells) for $24 \mathrm{~h}$, and the cell proliferation was assessed by the CCK-8 assay. (B) Kelly and SK-N-BE2 cells were pretreated with $5 \mathrm{mM} 3-\mathrm{MA}$ for $1 \mathrm{~h}$ and stimulated with $10 \mu \mathrm{M}$ ISO for $24 \mathrm{~h}$, and then the EdU assay was performed; scale bar, $100 \mu \mathrm{m}$. Student's unpaired t-test was used to assess the difference between two groups. Data represent the mean $\pm \mathrm{SEM}$ of three experiments; $\mathrm{P}<0.05$, ${ }^{* *} \mathrm{P}<0.01,{ }^{* * *} \mathrm{P}<0.001$. ISO, isoprenaline; 3-MA, 3-methyladenine.

prostate cancer, $\beta 2$-AR signaling can enhance breast cancer cell invasion (42). These findings revealed a promotive role of $\beta$-AR signaling in tumors. In our study, we demonstrated that the $\beta$-AR pathway plays a pro-survival role in NB cells, as the expression of $\beta 1$ - and $\beta 2$-AR was notably upregulated in NB specimens, compared to that in the samples of the less malignant tumors GN and GNB. Further functional studies suggested that $\beta 2-\mathrm{AR}$ is the key receptor responsible for NB cell growth. Clinical stage analysis revealed that although the $\beta 1$ - and $\beta 2$-AR expression levels were increased in the NB samples, they were not correlated with the different clinical stages of NB, indicating that $\beta$-AR signaling is important for the tumorigenesis of $\mathrm{NB}$, but may not be crucial for the metastasis of NB. There may be other 
A
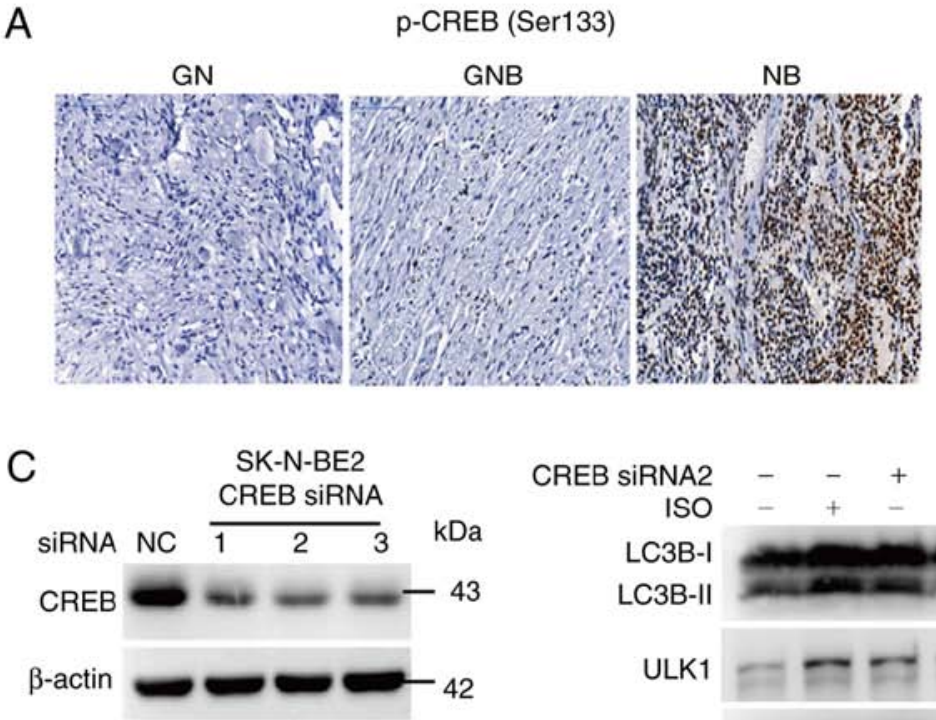

B
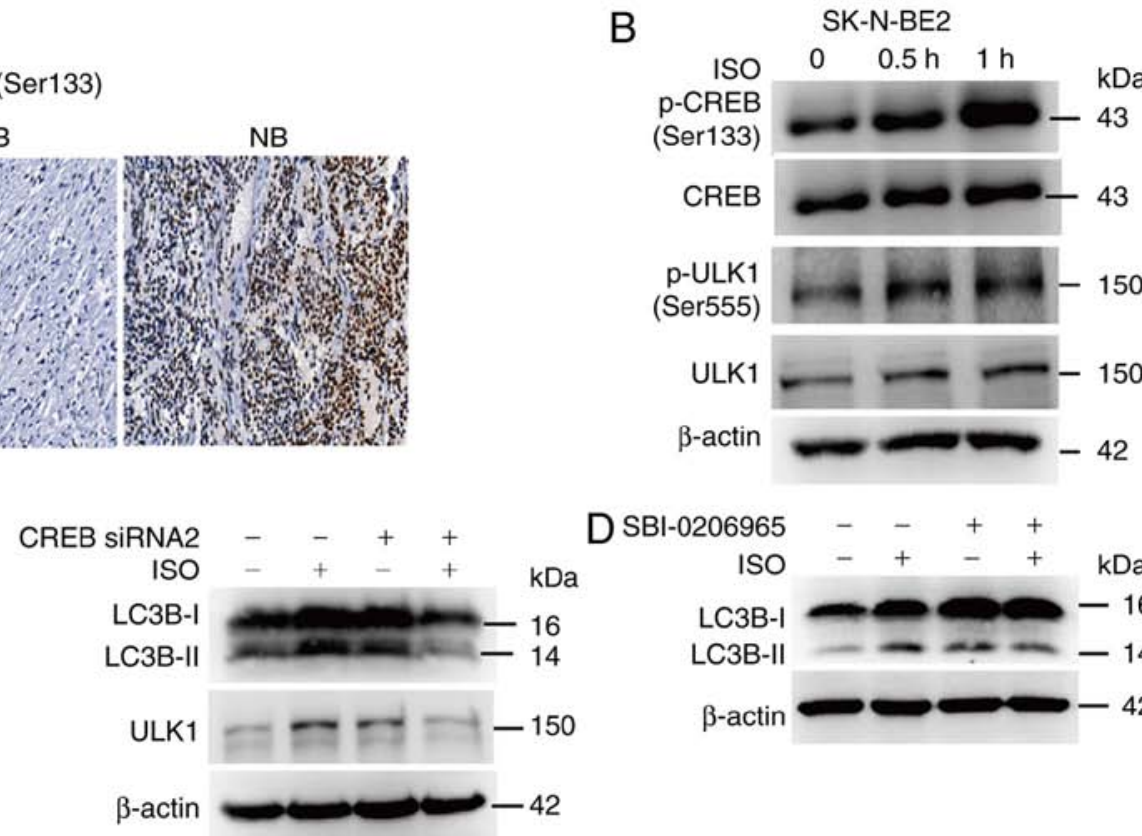

D SBI-0206965 - -++

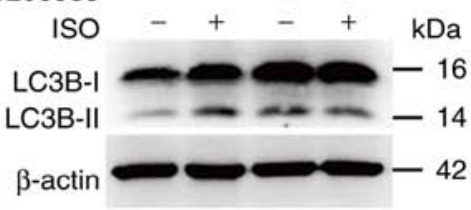

Figure 7. $\beta$-AR signaling activates autophagy via the CREB pathway in NB. (A) Expression of p-CREB was detected by IHC in the clinical samples of GN, GNB and NB; scale bar, $100 \mu \mathrm{m}$. (B) SK-N-BE2 cells were treated with $10 \mu \mathrm{M}$ ISO for 0.5 and $1 \mathrm{~h}$; western blotting was performed to detect p-CREB and p-ULK1 expression. (C) SK-N-BE2 cells were transfected with $100 \mathrm{nM}$ CREB siRNA for $24 \mathrm{~h}$ and then stimulated with $10 \mu \mathrm{M}$ ISO for $24 \mathrm{~h}$; western blotting assay was performed to detect the expression of ULK1 and LC3B-I and -II. (D) SK-N-BE2 cells were pretreated with $10 \mu \mathrm{M}$ SBI-0206965 for $1 \mathrm{~h}$ and then stimulated with $10 \mu \mathrm{M}$ ISO for $24 \mathrm{~h}$; the expression of LC3B-I and -II was detected by western blotting analysis. Experiments were replicated thrice and representative images are shown. IHC, immunohistochemistry; $\beta$-AR, $\beta$-adrenergic receptor; ISO, isoprenaline; NB, neuroblastoma; GN, ganglioneuroma; GNB, ganglioneuroblastoma; CREB, cAMP-response element binding protein; LC3-II, microtubule-associated protein 1 light chain 3-II.

signaling pathways regulating NB metastasis, which needs further investigations.

The role of autophagy in tumors is context-dependent and complex, and it is involved in the mediation of cancer stem cell viability, resistance to anoikis, drug resistance, and tumor growth and metastasis (43). Autophagy can promote or suppress tumor growth and progression in different types of cancer and microenvironmental settings. For instance, Yang et al demonstrated that blocking autophagy inhibited pancreatic ductal adenocarcinoma (PDAC) cell growth in an autochthonous mouse model, and that autophagy plays an important role in maintaining pancreatic tumor growth (44). In another study concerning non-small-cell lung cancer, Cai et al reported that CK1 $\alpha$ suppressed non-small-cell lung cancer growth by stabilizing PTEN and inducing autophagy and activating the tumor-suppressive PTEN/AKT/FOXO3a/Atg7 axis (45), suggesting an inhibitory role of autophagy in non-small-cell lung cancer. In the present study, we demonstrated that autophagy plays a promotive role in NB cell growth, as evidenced by the increased expression of the important autophagy markers ULK1, beclin-1 and LC3-II in clinical samples of NB, compared to that noted in GN and GNB. This suggests that autophagy activation is crucial for the tumorigenesis of NB. Further clinical correlation analysis revealed that the expression of ULK1, beclin-1 and LC3-II is positively correlated with the expression of $\beta 2-A R$ in clinical samples of NB, suggesting that $\beta 2-A R$ signaling may promote $N B$ cell growth by activating the autophagy pathway. Cellular assays demonstrated that $\beta 2$-AR promotes NB cell survival by stimulating the autophagy pathway, revealing that autophagy plays an important role in $\beta 2$-AR-mediated NB cell growth. Autophagy is also involved in tumor metastasis; however, in our study, we only investigated the effect of autophagy on NB cell growth, and not its role in NB cell invasion and metastasis. Hence, further studies are needed to evaluate the role of autophagy in the different clinical stages and metastasis of NB.

Our research on the related underlying mechanisms revealed that $\beta 2$-AR signaling activates autophagy via the downstream transcriptional factor CREB. As illustrated in our study, ISO promotes the phosphorylation of CREB, which leads us to speculate that $\beta$-AR activates autophagy via the CREB pathway. We found that siRNA-mediated knockdown of CREB abolished the ISO-induced accumulation of ULK1 and LC3-II. As ULK1 is a crucial upstream kinase that can initiate the autophagy pathway, we proposed that ISO activates autophagy through ULK1. Treatment of NB cells with the specific ULK1 inhibitor SBI-0206965 inhibited the ISO-induced enhancement of LC3B-II expression, suggesting that ISO induces autophagy via ULK1. In conclusion, our findings demonstrated the presence of a new regulatory mechanism underlying the involvement of $\beta 2$-AR and the autophagy cascade in NB cell growth.

In conclusion, the present study demonstrated that the $\beta 2$-AR pathway plays an important role in the progression of $\mathrm{NB}$, and $\beta 2-\mathrm{AR}$ signaling enhances NB cell proliferation via the activation of autophagy. Our findings clarify the existence of a novel crosstalk between autophagy and $\beta 2-A R$ in the regulation of NB cell growth, and provide a novel therapeutic strategy for treating NB more effectively by specifically targeting $\beta 2-\mathrm{AR}$ and autophagy. 


\section{Acknowledgements}

We thank Professor Bo Li for providing the neuroblastoma cell lines.

\section{Funding}

The present study was funded by the National Nature Science Foundation of China (grant nos. 81572342, 81770808, 81872165, 81570871, 81570764, 81600641 and 81602199); the National Key Sci-Tech Special Project of China (grant nos. 2013ZX09102-053 and 2015GKS-355); the Key Project of Nature Science Foundation of Guangdong Province, China (grant nos. 2015A030311043 and 2016A030311035); the Guangdong Natural Science Fund (grant nos.2014A020212023, 2014A030313073, 2015A030313029 and 2015A030313103); the Guangdong Science Technology Project (grant nos. 2017A020215075 and 2015B090903063).

\section{Availability of data and materials}

The analyzed datasets generated during the study are available from the corresponding author on reasonable request.

\section{Authors' contributions}

PJ and TY analyzed and interpreted the IHC staining results of the NB tissue microarray. JD, MH, JX and CL designed and drafted the manuscript. WQ, TZ, ZY, GG and XY finally approved the version to be published. All authors read and approved the final manuscript and agree to be accountable for all aspects of the research in ensuring that the accuracy or integrity of any part of the work are appropriately investigated and resolved.

\section{Ethics approval and consent to participate}

This study was approved by the Human Ethics Committee of the Affiliated Guangzhou Women and Children's Medical Center, Zhongshan School of Medicine. All patients gave informed consent before participation in this study.

\section{Patient consent for publication}

Not applicable.

\section{Competing interests}

The authors declare no competing interests.

\section{References}

1. Brodeur GM: Neuroblastoma: Biological insights into a clinical enigma. Nat Rev Cancer 3: 203-216, 2003.

2. Johnsen JI, Dyberg C, Fransson S and Wickström M: Molecular mechanisms and therapeutic targets in neuroblastoma. Pharmacol Res 131: 164-176, 2018.

3. Johnsen JI, Kogner P, Albihn A and Henriksson MA: Embryonal neural tumours and cell death. Apoptosis 14: 424-438, 2009.

4. Ratner N, Brodeur GM, Dale RC and Schor NF: The 'neuro' of neuroblastoma: Neuroblastoma as a neurodevelopmental disorder. Ann Neurol 80: 13-23, 2016.

5. Davidoff AM: Neuroblastoma. Semin Pediatr Surg 21: 2-14, 2012.
6. Matthay KK, Maris JM, Schleiermacher G, Nakagawara A, Mackall CL, Diller L and Weiss WA: Neuroblastoma. Nat Rev Dis Primers 2: 16078, 2016.

7. Chen AM, Trout AT and Towbin AJ: A review of neuroblastoma image-defined risk factors on magnetic resonance imaging. Pediatr Radiol 48: 1337-1347, 2018.

8. Cohn SL, Pearson AD, London WB, Monclair T, Ambros PF, Brodeur GM, Faldum A, Hero B, Iehara T, Machin D, et al: The international neuroblastoma risk group (INRG) classification system: An INRG task force report. J Clin Oncol 27: 289-297, 2009.

9. Luksch R, Castellani MR, Collini P, De Bernardi B, Conte M, Gambini C, Gandola L, Garaventa A, Biasoni D, Podda M, et al: Neuroblastoma (peripheral neuroblastic tumours). Crit Rev Oncol Hematol 107: 163-181, 2016.

10. Gonzalez Malagon SG and Liu KJ: ALK and GSK3: Shared features of neuroblastoma and neural crest cells. J Exp Neurosci 12: 1179069518792499, 2018.

11. Westermark UK, Wilhelm M, Frenzel A and Henriksson MA: The MYCN oncogene and differentiation in neuroblastoma. Semin Cancer Biol 21: 256-266, 2011.

12. Bell E, Chen L, Liu T, Marshall GM, Lunec J and Tweddle DA: MYCN oncoprotein targets and their therapeutic potential. Cancer Lett 293: 144-157, 2010.

13. Cruickshank JM: The role of beta-blockers in the treatment of hypertension. Adv Exp Med Biol 956: 149-166, 2017.

14. Tank AW and Lee Wong D: Peripheral and central effects of circulating catecholamines. Compr Physiol 5: 1-15, 2015.

15. Lukewich MK, Rogers RC and Lomax AE: Divergent neuroendocrine responses to localized and systemic inflammation. Semin Immunol 26: 402-408, 2014.

16. Padro CJ and Sanders VM: Neuroendocrine regulation of inflammation. Semin Immunol 26: 357-368, 2014.

17. Shakola F, Suri $\mathrm{P}$ and Ruggiu M: Splicing regulation of pro-inflammatory cytokines and chemokines: At the interface of the neuroendocrine and immune systems. Biomolecules 5: 2073-2100, 2015

18. Lan H, Hoos LM, Liu L, Tetzloff G, Hu W, Abbondanzo SJ, Vassileva G, Gustafson EL, Hedrick JA and Davis HR: Lack of FFAR1/GPR40 does not protect mice from high-fat diet-induced metabolic disease. Diabetes 57: 2999-3006, 2008.

19. Kim-Fuchs C, Le CP, Pimentel MA, Shackleford D, Ferrari D, Angst E, Hollande F and Sloan EK: Chronic stress accelerates pancreatic cancer growth and invasion: A critical role for beta-adrenergic signaling in the pancreatic microenvironment. Brain Behav Immun 40: 40-47, 2014.

20. Payne JK: State of the science: Stress, inflammation, and cancer. Oncol Nurs Forum 41: 533-540, 2014.

21. Dal Monte M, Casini G, Filippi L, Nicchia GP, Svelto M and Bagnoli P: Functional involvement of beta3-adrenergic receptors in melanoma growth and vascularization. J Mol Med (Berl) 91: 1407-1419, 2013.

22. Chen H, Liu D, Yang Z, Sun L, Deng Q, Yang S, Qian L, Guo L, $\mathrm{Yu} \mathrm{M}, \mathrm{Hu} \mathrm{M}$, et al: Adrenergic signaling promotes angiogenesis through endothelial cell-tumor cell crosstalk. Endocr Relat Cancer 21: 783-795, 2014.

23. Chen D, Xing W, Hong J, Wang M, Huang Y, Zhu C, Yuan Y and Zeng W: The beta2-adrenergic receptor is a potential prognostic biomarker for human hepatocellular carcinoma after curative resection. Ann Surg Oncol 19: 3556-3565, 2012.

24. Wu FQ, Fang T, Yu LX, Lv GS, Lv HW, Liang D, Li T, Wang CZ, Tan YX, Ding J, et al: ADRB2 signaling promotes HCC progression and sorafenib resistance by inhibiting autophagic degradation of HIF1 $\alpha$. J Hepatol 65: 314-324, 2016.

25. Magnon C, Hall SJ, Lin J, Xue X, Gerber L, Freedland SJ and Frenette PS: Autonomic nerve development contributes to prostate cancer progression. Science 341: 1236361, 2013.

26. Barron TI, Connolly RM, Sharp L, Bennett K and Visvanathan K: Beta blockers and breast cancer mortality: A population-based study. J Clin Oncol 29: 2635-2644, 2011.

27. Grytli HH, Fagerland MW, Fossa SD and Tasken KA: Association between use of beta-blockers and prostate cancer-specific survival: A cohort study of 3561 prostate cancer patients with high-risk or metastatic disease. Eur Urol 65: 635-641, 2014

28. Efeyan A, Comb WC and Sabatini DM: Nutrient-sensing mechanisms and pathways. Nature 517: 302-310, 2015.

29. Jiang $X$, Overholtzer $M$ and Thompson CB: Autophagy in cellular metabolism and cancer. J Clin Invest 125: 47-54, 2015. 
30. Wirawan E, Vanden Berghe T, Lippens S, Agostinis P and Vandenabeele P: Autophagy: For better or for worse. Cell Res 22: 43-61, 2012.

31. Scrivo A, Bourdenx M, Pampliega O and Cuervo AM: Selective autophagy as a potential therapeutic target for neurodegenerative disorders. Lancet Neurol 17: 802-815, 2018

32. Kim KH and Lee MS: Autophagy - a key player in cellular and body metabolism. Nat Rev Endocrinol 10: 322-337, 2014.

33. White E: The role for autophagy in cancer. J Clin Invest 125 : 42-46, 2015.

34. Menzies FM, Fleming A, Caricasole A, Bento CF, Andrews SP, Ashkenazi A, Fullgrabe J, Jackson A, Jimenez Sanchez M, Karabiyik C,et al: Autophagy and neurodegeneration: Pathogenic mechanisms and therapeutic opportunities. Neuron 93: 1015-1034, 2017.

35. Mizushima N: A(beta) generation in autophagic vacuoles. J Cell Biol 171: 15-17, 2005.

36. Guo JY, Karsli-Uzunbas G, Mathew R, Aisner SC, Kamphorst JJ, Strohecker AM, Chen G, Price S, Lu W, Teng X, et al: Autophagy suppresses progression of K-ras-induced lung tumors to oncocytomas and maintains lipid homeostasis. Genes Dev 27: 1447-1461, 2013.

37. Mathew R, Karp CM, Beaudoin B, Vuong N, Chen G, Chen HY, Bray K, Reddy A, Bhanot G, Gelinas C, et al: Autophagy suppresses tumorigenesis through elimination of p62. Cell 137: 1062-1075, 2009.

38. Dower CM, Bhat N, Gebru MT, Chen L, Wills CA, Miller BA and Wang HG: Targeted inhibition of ULK1 promotes apoptosis and suppresses tumor growth and metastasis in neuroblastoma. Mol Cancer Ther 17: 2365-2376, 2018.
39. Russell RC, Tian Y, Yuan H, Park HW, Chang YY, Kim J, Kim H, Neufeld TP, Dillin A and Guan KL: ULK1 induces autophagy by phosphorylating Beclin-1 and activating VPS34 lipid kinase. Nat Cell Biol 15: 741-750, 2013.

40. Seok S, Fu T, Choi SE, Li Y, Zhu R, Kumar S, Sun X, Yoon G, Kang Y, Zhong W, et al: Transcriptional regulation of autophagy by an FXR-CREB axis. Nature 516: 108-111, 2014.

41. Mierke CT: The fundamental role of mechanical properties in the progression of cancer disease and inflammation. Rep Prog Phy 77: 076602, 2014.

42. Creed SJ, Le CP, Hassan M, Pon CK, Albold S, Chan KT, Berginski ME, Huang Z, Bear JE, Lane JR, et al: $\beta 2$-adrenoceptor signaling regulates invadopodia formation to enhance tumor cell invasion. Breast Cancer Res 17: 145, 2015.

43. Mowers EE, Sharifi MN and Macleod KF: Autophagy in cancer metastasis. Oncogene 36: 1619-1630, 2017.

44. Yang A, Herter-Sprie G, Zhang H, Lin EY, Biancur D, Wang X, Deng J, Hai J, Yang S, Wong KK, et al: Autophagy sustains pancreatic cancer growth through both cell-autonomous and nonautonomous mechanisms. Cancer Discov 8: 276-287, 2018.

45. Cai J, Li R, Xu X, Zhang L, Lian R, Fang L, Huang Y, Feng X, Liu X, Li X, et al: CK1 $\alpha$ suppresses lung tumour growth by stabilizing PTEN and inducing autophagy. Nat cell Biol 20: 465-478, 2018.

This work is licensed under a Creative Commons Attribution-NonCommercial-NoDerivatives 4.0 International (CC BY-NC-ND 4.0) License. 